\title{
Koruyucu diş hekimliğinde florürlerin kullanımında değişen bakış açısı
}

\author{
Gamze Aren(0000-0002-1479-0723) ${ }^{\alpha}$
}

Selcuk Dent J, 2020; 7: 113-117 (Doi: 10.15311/selcukdentj.413680)

Basvuru Tarihi: 09 Nisan 2018 Yayına Kabul Tarihi: 27 Kasım 2018

\begin{abstract}
ÖZ
Koruyucu diş hekimliğinde florürlerin kullanımında değişen bakış açısı

Diş sağlığı konusunda hastalar ve diş hekimlerinin artan farkındalıklarına rağmen, bilgi ve tutumlarının iyileştirilmesi halen gereksinim duyulan konulardan biridir. Hastalar için ağız sağlığının öneminin anlaşıması son yıllarda dişlerin remineralizasyon ajanları ve ürünlerindeki artışla birlikte görülmüştür. Buna eş zamanlı olarak, in vivo ve in vitro dişlerin remineralizasyon ve demineralizasyonlarına yönelik çalışmalarının yayınlanması da sürdürülmüştür. Florürlerin diş minesinin çözünmesini azaltarak remineralizasyonunu artırma yolu ile çürükten korunmada etkili ajan oldukları bilinmektedir. Florür tedavilerinin genelde diş minesinin demineralizasyondan korunması ve remineralizasyonunun artııılmasına yardımcı olarak etkili oldukları açıktır. Bu makalenin amacı, florür tedavileri ile diş remineralizasyonununda değişen bilgi ve yaklaşımın gözden geçirilmesidir.
\end{abstract}

\section{ANAHTAR KELIMELER}

Ağız sağlığı, diş remineralizasyonu, florür

Araştırma sistematik bir temel üzerinde insan, kültür ve toplumun bilgi birikimini arttırmaya yönelik gerçekleştirilen ve bu birikimi de yeni uygulamaların tasarlanması için kullanan yaratıcı bir eylemdir. ${ }^{1}$ Diş hekimliği alanında yapılan araştırmalar da özellikle koruyucu yaklaşımın benimsenmesi açısından perspektifi olumlu yönde etkileyerek önemli katkılar sağlamıştır.

İşlevsel açıdan bakıldığında pratik diş hekimliğinin oldukça sınırlı olduğu dönem; İkinci dünya savaşı sonrası giderek zenginleşen ülkelerde yüksek şeker içerikli ürün tüketimindeki artışın ortaya çıktığı dönemdir. "Diş çürüğü pandemisi" nin yaşandığı bu dönemde dişlerin sadece mekanik temizliği ön planda tutulmuştur. İnsanların diş çürüğü, genelde diş ağrısından şikayetçi oldukları bu dönemde hastaların yapacağı ortalama ağız hijyeni uygulamalarının ağız sağlıklarında yeterli olmayacağı yönünde derlemeler bile düzenlenmiştir. ${ }^{2}$ Pratikte diş hekimleri hemen tüm randevularında hastalarına çekim ve invaziv restorasyon

\section{ABSTRACT}

Changing perspectives in the use of fluoride in preventive dentistry

In spite of the increasing awareness of dental health among patients and dentists, there is still a need to improve the knowledge and attitudes related to this condition. Understanding the importance of oral health care for patients has seen a steady increase in the number of tooth remineralisation agents and products over recent years. Concomitantly, there has been continued publication of both in vivo and in vitro tooth remineralisation and demineralisation studies. Fluoride has long been known to be effective in protecting the dental enamel from caries by reducing enamel dissolution and enhancing enamel remineralisation processes. It is clear that fluoride treatments are generally effective in helping to protect the dental enamel from demineralisation and enhancing remineralisation. The purpose of this paper is to review changing knowledge and approach for tooth remineralisation with fluoride treatments.

\section{KEYWORDS}

Oral health, tooth remineralisation, fluoride

uygulamalarına odaklandıkları için genelde çözüm olarak total protezleri önermekte idiler.

Diş çürüğünün önlenmesinde floridlerin kullanılmaya başlanması

Florürün diş çürüğünü önleme konusunda keşfedilmeye başladığı 1930' lu yıllara bakıldığında olumsuzlukların giderek değişmeye başladığı dönem karşımıza çıkar. Her ne kadar florür içeren biyouyumlu macunlar 1960- 1970' li yillara gelene dek kullanıcılar için uygun olmaktan uzak olsalar da hasta ve diş hekimler macununun potansiyeline ikna olduktan sonra, florürler de farklı uygulama biçimleri ile toplumun büyük çoğunluğu tarafından benimsenmiştir. İçme sularına, tuzlara florürler eklenmiş, yüksek konsantrasyonlarda "lokal" uygulamalarda kullanılmıştır. Hatta süt ve şekerin içerisine eklenmesi yönünde ciddi çalışılarak, okullarda diş hekimleri de sınıfları sık sık ziyaret ederek florür uygulamaları yapmışlardır.

\footnotetext{
${ }^{\alpha}$ İstanbul Üniversitesi, Diş Hekimliği Fakültesi, Pedodonti Anabilim Dalı, İstanbul
} 
Florürlerin diş çürüklerini önlemedeki etkinliklerinin tam olarak anlaşılamamış olması bu tür girişimlerin yaygın uygulanmasına neden olmuştur. İleri sürülen hipotez, florürün dişlerin yapısında bulunan kalsiyum fosfat minerallerine sıkıca bağlanması yönünde olurken dişlerin en dış tabakasında bulunan florürden zengin mineral yapının asitler karşısında dişlerin çözünürlüğünü azalttığı, kimyasal modifikasyonun da bu açıdan daha az diş çürüğüne yol açtığı yönünde olmuştur. Reklamlarda “ florür dişlerinizi sertleştirir" şeklindeki popüler terimi bolca kullanılmış ve oluşan florür birleşiminin yaşam boyu koruma sağladığına inanıldığı için dişler ağız ortamına sürer sürmez florürlenmesi amaçlanmıştır.

\section{Fluorürün etki mekanizması}

Dişlerdeki florür bileşimi paradigması üzerindeki şüpheleri arttıran iki bulgu çürüğün engellenmesine mantıklı açıklama getirmiştir. İlk olarak çeşitli araştırmalar ile, asidik pH'da dişlerin etrafındaki ağız sıvılarında oldukça düşük oranlarda bulunan florürün (yaklaşık litrede $0.1 \mathrm{mg}$ florid) dişlerin çözünürlüğünü belirgin olarak azalttığı gösterilmiştir.,4 Benzer florür oranlarının aslında çürüğün erken evrelerinde oluşan poröz alanlarda depolanan kalsiyum fosfat minerallerinin tükürükten presipitasyonunu da arttırdığı bulunmuştur. Orijinal florür paradigmasını altüst eden ikinci bulgu ise bir kaç yıl sonra Norveçli Øgaard ve arkadaşları tarafından köpekbalığı dişlerinde bulunan tam florürlü minenin sürpriz şekilde florürlü olmayan mineden sadece çok az miktarda çözünür olduğunun bildirilmesi olmuştur. ${ }^{5}$ İşte tüm bu bulgular florürün çürüğü önleme mekanizması üzerinde yapılan çalışmalardaki uzlaşıyı yıkan unsurların temelini oluşturmuştur.

Florürlerin esas etkisinin diş oluşumu sırasında mine yapısına sistemik olarak katılmasında değil ağız boşluğunda lokal olarak bulunmasında olduğu sonucuna varılmıştır. $^{6}$ Burada ısrarla belirtmek gerekir ki küçük yaştaki çocukların dişlerine florür yüklenmesi, ya da florür tableti reçetelendirilmesi (genelde de çiğnemeden yutturulur); florür verilmesindeki en etkin yol değildir. Pratik olarak belirtmek gerekirse, artık topikal florür uygulamalarında okul sınıflarında oluşturulan muayenehane ortamları yerine florürlü diş macunu ile çocukların düzenli diş fırçalamasının sağlanması çok daha yararlı olacaktır. Florürlü diş macunlarıyla yapılan düzenli fırçalama sonucu florür düzeyi; hem demineralizasyona hem de re-mineralizasyona yararlı olacak şekilde hafifçe yükselebilir. Ancak bu yeni mantığın gerek diş hekimleri gerekse hastalarına bazı sorumluluklar getireceği açıktır. Örneğin hastalar uyumlu olmalı ve dişlerini düzenli olarak fırçalamalıdır. Özellikle Kuzey Avrupa ülkelerinde çocuklara doğru ve etkili diş fırçalama alışkanlığının kazandırılmasını amacına yönelik olarak kurulan "fırçalama klinikleri" bunun en iyi örneğini oluşturur. Halen günümüzde yüksek konsantrasyonda topikal florür uygulamaları kliniklerde yapılsa da artık çok daha seçici davranılarak ağızlarında" yüksek çürük" barındıran çocuklarda tercih edilmektedir. Muayenehane ortamında uygulamaların finansal getirilerini ön planda tutan diş hekimleri açısından tüm bu bulguların sonuçları pratikte şaşırtıcı olsa da ne yazık ki gerçekler farklı yöndedir.

Başlangıç aşamalarında diş çürüğünün geri dönüşebilir niteliği, çözünme ile onarım arasındaki bir dengesizlikten kaynaklanan diş çürüğünün her iki aşamasının da florürlerden etkileniyor olması gibi noktalar, araştırıcıları ağız boşluğunu taklit eden çeşitli modelleri yaratmaya yönlendirmiştir. 1982'de ten Cate ve Duijsters'in $\mathbf{~ p H}$ siklusu ile ilgili ilk makaleyi yayınlamalarının ardından özellikle doz etkili çalışmaların sonuçları çocuk macunlarında bulunan florür oranlarının düşürülmesi uygulamasını gündeme getirmiştir. ${ }^{7}$ Hemen ardından dünyada halen sıklıkla kullanılan, O'Reilly ve Featherstone' un 1987'de geliştirdiği deneysel koşullarda $\mathrm{pH}$ siklusu verilerinin in vivo bulgularla bağlantılı olabildiğini gösteren özel çalışmaları yayımlanmıştır. ${ }^{8}$

Çürük gelişiminin bireyler arasında oldukça değişkenlik göstermesi, Koulourides ve arkadaşları tarafından 1974'te çıkış mantığı ağız içi bulguların ağız dışından çok daha hassas olduğu düşüncesine dayanan ilk araştırmanın gönüllülerin diş mineleri üzerinde gerçekleştirilmesini gündeme getirmiştir. ${ }^{9}$ 1985'e gelindiğinde ise geliştirilen yeni ağız içi modeli ile gönüllülerin ağızlarına uygulanan parsiyel protezlere yerleştirilen mine ve dentin parçalarının üzerinde çeşitli ürünlerin etkileri değerlendirilmiştir. Yöntem macunların etkilerinin aydınlatılması konusunda oldukça yararlı olmuş ancak en önemli bulgusu, çürüğün kişiden kişiye gösterdiği değişkenliğin anlaşılması olmuştur. Gerek bakteriyolojik gerekse fizyolojik açıdan çok daha farklı parametrelerin araştırılmasının zorunlu olduğu düşüncesinin yanında çok daha geniş gruplar üzerinde çalışılmasının gerektiği vurgulanmıştır. ${ }^{10}$

Değişen yaşam şartları ile Kuzey Avrupa ülkelerinde olduğu gibi diş çürüğünün bazı ülkelerde azalabilirken bazılarında artış göstermesi üzerinde araştırıcıların hipotezleri; giderek artan sayılarda insanların kötü yeme alışkanlığına bağlı olarak, aşırı kilo ve obesite ile mücadele etmekte olduğu ekseninde toplanmıştır. Burada yöneltilen temel soru " eğer bu insanlar yeme alışkanlıklarını daha sık karyojenik bölümlerle değiştirir iseler, floridler hala diş çürüğünü önlemede etkin biçimde yardımcı olabilecek mi?" şeklindedir.

Mine lezyonlarının reminerilizasyonunu artırarak etki gösteren florürlerin bu etkisi, atıştırmalar arasındaki remineralizasyon bölümlerinin süresiyle sınırlı kaldığında yeterli olmayacaktır. Çeşitli çalışma sonuçları sağlıklı bir diş dizisinin korunmasında florür etkisinin karyojenik öğün sayısındaki artış durumunda (yaklaşık 6 ya kadar) korunabileceği, 
ancak bu sayı aşıldığında çürükle onarım arasındaki dengenin çürüğe doğru kayarak diş çürüğünün gelişmeye başlayacağı yönünde olmuştur. ${ }^{10}$

\section{Bakteriyel dental plak}

$\mathrm{Bu}$ alanda çalışmaya odaklanan farklı araştııııılar konuya çok değişik açılardan baksalar da en önemli bulgu ağız ekosisteminin düşünülenden çok daha karmaşık bir yapıya sahip olduğudur. ${ }^{11,12}$ Kimyasal, bakteriyel ve konağa ait fizyolojik süreçlerin tümünün birbirleriyle bağlantılı olması yanında diş çürüğünün önemli bir genetik bileşeni de bulunmaktadır. ${ }^{13}$ Ağız mikrobiyomunda yer alan bakterilerin büyük bir olasılıkla tüm vücuttaki bilişsel fonksiyonları kontrol eden barsak mikrobiyomu ile etkileşimde olabileceği düşünülmektedir. ${ }^{14} \mathrm{Bu}$ da bilimde bir sistem biyolojisi yaklaşımının benimsenmesi mantığına iyi bir örnektir. Ağız ekosistemi de aydınlatıması zorunlu olan en önemli vücut bileşenlerinden birisidir.

Diş çürüğü mineralize dişin yıkımına yol açan biyofilm kaynaklı bir hastalıktır. Karyojenik biyofilmin oluşumu konağın diyetine bağlı olduğu için diş çürüğünde mikroorganizmaların varlığı gerekli ancak tek başına yeterli değildir. Ağızda, pelikı kaplı diş yüzeyine hızla yapışan erken yerleşen mikroorganizmalarla mikrobiyal etkileşimler başlar ve daha sonra diğerleri ile birleşir. Bu süreç sırasında, çeşitli türler fiziksel ve metabolik olarak ilk biyofilm topluluğunu şekillendirmek için etkileşime girerler. Bazı etkileşimler, karyojenik bakterilere karşı (örneğin Streptococcus mutans) komensallar gibi (örneğin Streptococcus gordonii ve Streptococcus salivarius) hidrojen peroksit ve bakteriyosinleri "kimyasal silahlar" olarak salgılayarak ya da alkali üreterek asidifikasyonun zararlı etkilerini tersine çevirme yoluyla rekabet edecekleri için faydalıdır (Liu et al 2012; Merrit and Qi 2012; Qi and Kreth 2017). Ancak, komensal ve patojenler arasındaki denge sık şeker tüketimi ve kötü ağız hijyeni ile bozulabilir.

Florürler mevcut durumda çürükten korunmanın temelini oluştursalar da (O'Mullane et al 2016), tam korunma sağlamazlar(Featherstone and Domejean 2012, Liu 2018). En büyük etkinlikleri dişlerin remineralizasyonunu arttırmaları ve demineralizasyonunu azaltmaları olan florürlerin bakteriyel metabolizmayı inhibe edici özellikleri olmakla birlikte (Marquis et al 2003) biyofilmlere karşı etkileri sınırlıdır (Liu 2018).

\section{Diş hekimliğinde halk sağlığı programları}

Yıllardır yapılan sayısız araştırma ve sunulan yeni çürük önleyici ürünlere karşın çürüğün ortadan kaldırıması henüz pek mümkün görünmemektedir. Diş hekimleri tarafından yapılan işlemlerin çoğunluğunu halen hastalarının çürükten korunma uygulamaları yanında kavite restorasyonları oluşturmaktadır.
Yaşam kalitesini olumsuz etkileyen bir etken olan diş çürüğü ülkemizde de dünya üzerindeki diğer pek çok ülkede olduğu gibi sıkıntı yaratmaktadır. Gelişmekte olan ekonomilerde genellikle ağız sağlığının iyileştirilmesi konusunda koruyucu tedbirler halk sağlığı gündeminde belirgin yer almamaktadır.

Günümüzde diş çürüğünün önlenmesi yönünde hangi çalışmaların öncelik taşıdığı, ağız boşluğundaki süreçte etkili olabilecek bilgilerin neler olabileceği sorgulanmaktadır. ${ }^{10}$ Lancet dergisi 2009 'da hazırladığı başyazıda ağız sağlığının küresel sağlığın göz ardı edilen bir alanı olduğu, geleneksel olarak ulusal politikaları hazırlayanların ilgi alanlarında son sıralarda yer aldığı, kronik hastalıkların önlenmesinde halk sağlığı sistemlerine 'ağız hastalıklarının önlenmesi taahhüdünün politik olarak entegre edilmesinin gerekli olduğu' belirtilmiştir. İyi ağız sağlığı ' herkesin işi' olmalıdır. ${ }^{15}$

Ağız sağlığı ve hastalığının yaygın farkındalık ve finansal destek oluşturmaya başladığına ilişkin göstergeler de bulunmakla birlikte iyi bir genel sağlık için iyi ağız sağlığının zorunluluk olduğu kimse tarafından yadsınamaz. Buna en iyi örnek araştırma enstitülerinden oluşan bir konsorsiyum ve katılımcıların yer aldığı geniş panel ile gerçekleştirilen kapsamlı İnsan Mikrobiom Projesinde [2012] ağız boşluğunun önemli bir yer tutmasıdır. Bu çalışmalarda insan vücudunda 9'u ağız boşluğunda bulunan 18 bölgenin bakteri bileşimleri analiz edilmiştir. Oldukça büyük finans kaynaklı bu projenin gerekçesini, hastalıktan hangi bakterilerin sorumlu olduğunun anlaşılmasında, sağlıklı bir popülasyon içindeki varlıklarının öncelikli bir envanterinin yapılması oluşturmuştur.

\section{Hasta uyumunda karşılaşılan güçlükler}

Ağız sağlığına yönelik önemli ayrıntılara yeni yeni ulaşırken, hastalarımızı doğru biçimde koruma ve motive etme konusunda tereddütler yaşadığımız da bir gerçektir.

Ağız sağlığının korunmasında temel görüş, davranış yönlendirilmesine çok daha fazla ilgi göstererek bu konuda ısrarla konuşmanın gerekliliğidir. Peki hastalarımızı daha uyumlu bir yaşam biçimi konusunda nasıl motive edebiliriz? Ya da, küresel düzeyde toplumun tüm katmanlarındaki bireylerin kullanılabileceği hesaplı ağız bakım ürünleri ile ağız sağlığı programlarını nasıl oluşturabiliriz? Ağız sağlığına yönelik olarak en temel uygulama olan diş fırçalama alışkanlığı en erken ve etkili nasıl kazandırılır? Bu alanda anne adaylarında tutum ve davranış değişiklikleri oluşturulması dolayısıyla bebeklerinde kötü ağız sağlığının önlenmesi amaçlı yapılan ağız sağlığı eğitimi çalışmalarında başarının değişkenliği düşündürücüdür. Bazı olumlu davranışlar rahatıkla benimsenirken bazı olumsuz 
alışkanlıklardaki ısrarın nedeni henüz anlaşılabilmiş değildir. Bu yüzden ağız sağlığını iyileştirmeye yönelik programlar uygulanırken öncelikli olarak neden diğerlerinin değil de bazı sağlık davranışlarının benimsendiğinin saptanması önemlidir.

Asında, bir annenin davranışlarını etkileyen ve riskli hareketlerinin nedenini açıklayacak olan önemli belirleyicilerin iyi tanınması gereklidir. Araştırma ile saptanamayan örneğin hamile anne ile ilgili kültürel inanç ve etkilerin de içinde bulunduğu sağlığın daha geniş sosyal belirleyicileri' ${ }^{16,17,18}$, aile içinde karar vermedeki özerklik seviyesi, başa çıkma becerileri ve destekleyici iletişim bağlantıları da ${ }^{19-20}$ anne adayının geçmiş diş hekimi deneyimleri, kişisel diş bakımı ve konu ile ilgili bilgilere erişim özelliklerinin yanı sıra karmaşa yaratabilir. Bir bebekte bakterilerin yerleşimi, düzeyleri ve erken çocukluk çağı çürükleri belirlenirken bebeğin beslenmesine yönelik tutum ve davranışlardan sadece belirli olanlarının değil bu alışkanlıkların zamanlaması ve sıklığının da öncelikli önem taşıdığı gözlenmiştir.

Bazı alışkanlıkların bebeğin gelişim aşamasına bağı olarak kötü bir ağız sağlığı oluşumunda daha yüksek bir risk yaratma olasılığı taşıdığı belirlense de, diğer alışkanlıkların da çocuğun yaşı ne olursa olsun kötü bir ağız sağlığı oluşumunda riski arttırdığı gösterilmiştir. ${ }^{21}$

Sonuçta ağız sağıı̆ı alanında bazı başarılar elde edilse de halen pek çok kişi için büyük yarar sağlayacak çok geniş bir potansiyel bulunmaktadır. Diş hekimleri uygun önerilerde bulunarak hastalarının diş fırçalama etkinliklerini arttırma konusunda net bir role sahiptir ve gelecekte bu işlevlerini mesleklerinin önemini arttıracak ve destekleyecek yönde geliştirmeleri de gerekmektedir.

\section{Geleceğe yönelik bakış açısı}

Diş çürüğü, florürlerin keşfine rağmen günümüzde halen önemli bir halk sağlığı problemi olmayı sürdürmektedir. Her ne kadar diş minesinin demineralizasyonunu azaltmada etkili olsa da, florürlerin biyofilmler üzerindeki etkinlikleri kısıtlıdır. Mevcut antimikrobiyaller sağlıklı bir ağızla uyumlu mikrobiyal oranlarda mevcut durumun korunmasına yardımcı olabilirler, ancak koşullar diş çürüğüne elverişli hale dönüştüğünde etkinlikleri yetersizdir. ${ }^{22}$ Gerçekten de karyojenik biyofilmleri tedavi etmek güçtür. Bakteriler genellikle, visko elastisite veren, oldukça yapışık, yüzeye bağlı ve uzaklaştıııması güç ekstrapolisakkarid bir matrikse gömülür. Dahası matriksin difüzyon ayarlayıcı özellikleri tükürüğün tamponlayıcı varlığına rağmen, polimikrobiyal etkileşimler sırasında yerleşik mikropların antimikrobiyallere dirençli olduğu, biyofilm-diş arayüzünde lokalize asitleştirme oluşturan heterojen bir ortam sağlar. Bu yüzden kariojenik biyofilmlerin fiziksel ve biyolojik karmaşıklığı yeni terapötik yaklaşımlar tasarlanırken göz önünde bulundurulmalıdır. Diş çürüğünün önlenmesinde geleneksel antimikrobiyal yöntemler klinik etkinlikte bu kimyasal özellikler baz alınırsa sınırlı etkiye sahiptir. Bu bağlamda geleceğe yönelik terapötik stratejiler biyofilmin mikro çevresine spesifik, matriks ve matrikse gömülü bakterilerin her ikisinin de patojenitelerini ortadan kaldıracak ve çevre dokulara minimal sitotoksik olacak şekilde düzenlenmelidir. Mevcut biyofilmlere ilaç penetrasyonunun arttırılması, yüksek antibakteriyal etkinliğin sağlanarak ilaç direnci oluşumunun azaltılması yoluyla matriksin azaltılması sağlanabilir.

Son yıllarda karyojenik patojenleri hedef alan türe özgü anti mikrobiyal peptitler, arginin metabolizması yolu ile biyofilm pH'sının düzenlenmesi, yüksek hızdaki su spreyleri ile fiziksel olarak ayrıştırma, bakteriyel yok etme ve ekstrasellüler polisakkaritlerin sindirilmesinin sinerjik kombinasyonu gibi farklı uygulamaları da içeren biyofilm karşıtı yeni stratejiler geliştirilmiştir. Daha da ötesi, asidik pH değerlerine cevaben "uyaranla tetiklenen salınım ya da aktivasyon" yoluyla in situ seçiciliği gelişmiş ve kontrollü ilaç veren/ güçlendiren yeni (nano) teknolojiler oluşturulmuştur.

Biyofilm karşıtı uygulamalara özgü diğer etkileyici yaklaşımlar, nano kaplamalar, yüzey modifikasyonları, biyo/siliko tarayıcı bazlı küçük moleküller de dahil olmak üzere dikkate değer bir hızda gelişmektedir. ${ }^{23-25}$ Yine de, etki ve toksisite mekanizmasının daha derinden anlaşılabilmesi için in vivo modellerin kullanılması ve etkinliğinin klinik çalışmalarla doğrulanması gerekmektedir. Ağızda topikal uygulanan ajanların zayıf tutuculuğunun yanında yüzey kimyasını değiştirerek hızla uzaklaşmasına yol açan tükürüğün varlığı da diğer bir sorun yaratan bileşendir.

Gelecek yöntemler maksimum etkinlik ve özgüllüğe ulaşmada minimal toksisite ve uzun süreli terapötik etkilere odaklanmalıdır. Sonuç olarak bu ürünlerin toplumun tüm katmanlarına yayılmasında diş hekimlerine önemli görevler düşmektedir. 


\section{KAYNAKLAR}

1. Frascati Manual: Proposed Standard Practice for Surveys on Research and Experimental Development, 6th edition: OECD Publications Service, 2, rue André-Pascal,75775 Paris Cedex 16, France. 2002, 30.

2. Bellini HT, Arneberg $P$, von der Fehr FR: Oral hygiene and caries. A review. Acta Odontol Scand 1981; 39: 257-65.]

3. Ten Cate JM, Duijsters PP: Influence of flüoride in solution on tooth demineralization. I. Chemical data. Caries Res 1983a;17: 193-9.

4. Ten Cate JM, Duijsters PP: Influence of flüoride in solution on tooth demineralization. II. Microradiographic data. Caries Res 1983b;17: 5139.

5. Øgaard B, Rölla G, Ruben J, Dijkman T, Arends J: Microradiographic study of demineralization of shark enamel in a human caries model. Scand $\mathrm{J}$ Dent Res 1988; 96: 209-11.

6. Fejerskov $\mathrm{O}$ : Changing paradigms in concepts on dental caries: consequences for oral health care. Caries Res 2004; 38: 182-91.

7. Ten Cate JM, Duijsters PP: Alternating demineralization and remineralization of artificial enamel lesions. Caries Res 1982; 16: 201-10.

8. O'Reilly MM, Featherstone JD: Demineralization and remineralization around orthodontic appliances: an in vivo study. Am J Orthod Dentofacial Orthop 1987; 92: 33-40.

9. Koulourides T, Phantumvanit P, Munksgaard EC, Housch T: An intraoral model used for studies of fluoride incorporation in enamel. J Oral Pathol 1974; 3: 185-96.

10.Ten Cate JM. Models and role models. Carie Res 2015; 49(suppl 1): 3-10.

11. Keijser BJ, Zaura E, Huse SM, van der Vossen JM, Schuren FH, Montijn RC, ten Cate JM, Crielaard W: Pyrosequencing analysis of the oral microflora of healthy adults. J Dent Res 2008; 87: 1016-20.

12.12-Zaura E, Keijser BJ, Huse SM, Crielaard W: Defining the healthy 'core microbiome' of oral microbial communities. BMC Microbiol 2009; 9: 259.

13. Vieira AR, Modesto A, Marazita ML: Caries: review of human genetics research. Caries Res 2014; 48: 491-506.

14.Grenham S, Clarke G, Cryan JF, Dinan TG: Braingut- microbe communication in health and disease. Front Physiol 2011; 2: 94

15. Oral health: prevention is key. Lancet 2009; 373 (9657): 1.

16. Fisher-Owens SA, Gansky SA, Platt LJ et al. Influences on children's oral health: a conceptual model. Pediatrics 2007; 120: 510-20.
17. Hilton IV, Stephen S, Barker JC, Weintraub JA. Cultural factors and children's oral health care: a qualitative study of carers of young children. Community Dent Oral Epidemiol 2007; 35: 42938.

18.Flores G, Tomany-Korman S. Racial and Ethnic Disparities in Medical and Dental Health, Access to Care, and Use of Services in US Children. Pediatrics 2008; 121: e286-98.

19.Reisine S, Douglass J. Psychosocial and behavioural issues in early childhood caries. Community Dent Oral Epidemiol 1998; 26: 32 44.

20. Smith P, Freeman R. Living in a sweetie culture: scottish parents' difficulties in maintaining their children's oral health. Health Ed 2009; 68: 25565.

21.Leong PM, Gussy MG, Barrow SYL, De SilvaSanigorski A, Waters $E$. A systematic review of risk factors during first year of life for early childhood cariesInternational Journal of Paediatric Dentistry 2013; 23: 235-50.

22. Liu Y, Ren Z, Hwang G, Koo H. Therapeutic Strategies Targeting Cariogenic Biofilm Microenvironment. Adv Dent Res 2018; Feb; 29(1): 86-92.

23. Allaker RP, Memarzadeh K. Nanoparticles and the control of oral infections. Int $J$ Antimicrob Agents 2014; 43(2): 95-104.

24. Besinis A, De Peralta T, Tredwin CJ, Handy RD. Review of nanomaterials in dentistry: interactions with the oral microenvironment, clinical applications, hazards, and benefits. ACS Nano 2015; 9(3): 2255-89.

25. Paula AJ, Koo H. Nanosized building blocks for customizing novel antibiofilm approaches. J Dent Res 2017; 96(2):128-36.

Yazışma Adresi:

Prtof. Dr. Gamze AREN

İstanbul Üniversitesi

Diş Hekimliği Fakültesi

Pedodonti AD, İstanbul

E-mail : gamzearen@hotmail.com 